Fundamentos ontológicos de la organización del conocimiento:

la teoría de los niveles integrativos aplicada al orden de cita

\title{
Ontological foundations in knowledge organization: the theory of integrative levels applied in citation order
}

\author{
Claudio GNOLI \\ University of Pavia, Science and Technology Library, via Ferrata 1, 27100 Pavia, Italy, gnoli@aib.it
}

\section{Resumen}

El campo de la organización del conocimiento puede ser descrito como compuesto de cuatro capas: teoría, sistemas, representación y aplicación. Esta ponencia se centra en las relaciones entre la teoría y los sistemas de organización del conocimiento. Se reconoce que la estructura de los sistemas de organización del conocimiento es producto de una mezcla de factores ontológicos, epistemológicos y pragmáticos. Sin embargo, sistemas diferentes asignan prioridades diferentes a cada factor. Un enfoque más ontológico, aunque no ofrece soluciones rápidas para los grupos particulares de usuarios, sí producirá sistemas de aplicación amplia y de larga duración, al basarse en principios generales y compartidos. Se plantea el caso de la teoría ontológica de los niveles de integración, que ha sido considerada una fuente útil para las clasificaciones generales durante varias décadas, y está siendo actualmente implementada en el sistema Clasificación de Niveles Integradores. Esta teoría produce una secuencia de clases principales modelando un orden natural en los fenómenos. Este orden tiene efectos interesantes también en otras características del sistema, como el orden de cita de los conceptos dentro de los compuestos. Como muestra la teoría analítica de facetas, es útil que el orden de cita siga el principio de inversión, respecto al orden de las tablas. A la luz de la teoría integradora de los niveles, este principio también adquiere un significado ontológico, no solo para las facetas sino también para las relaciones de fase: los fenómenos de nivel superior deberían ser citados primero, pues son relevantes a un mayor nivel de generalidad, mientras que los niveles inferiores frecuentemente juegan el papel de sus componentes. Este principio general, sin embargo, debería complementarse con la noción de tema principal, permitiendo que se pueda promover un fenómeno de nivel inferior a la posición principal en los casos en los que sea el foco principal de documento. La integración de estos principios debería producir resultados óptimos en la ordenación de contenidos de conocimiento.

Palabras clave: Sistemas de organización del conocimiento. Ontología. Epistemología. Teoría de los niveles integrativos. Tema principal. Orden de cita.

\begin{abstract}
The field of knowledge organization (KO) can be described as composed of the four distinct but connected layers of theory, systems, representation, and application. This paper focuses on the relations between KO theory and KO systems. It is acknowledged how the structure of $\mathrm{KO}$ systems is the product of a mixture of ontological, epistemological, and pragmatical factors. However, different systems give different priorities to each factor. A more ontologically-oriented approach, though not offering quick solutions for any particular group of users, will produce systems of wide and long-lasting application as they are based on general, shareable principles. I take the case of the ontological theory of integrative levels, which has been considered as a useful source for general classifications for several decades, and is currently implemented in the Integrative Levels Classification system. The theory produces a sequence of main classes modelling a natural order between phenomena. This order has interesting effects also on other features of the system, like the citation order of concepts within compounds. As it has been shown by facet analytical theory, it is useful that citation order follow a principle of inversion, as compared to the order of the same concepts in the schedules. In the light of integrative levels theory, this principle also acquires an ontological meaning: phenomena of lower level should be cited first, as most often they act as specifications of higher-level ones. This ontological principle should be complemented by consideration of the epistemological treatment of phenomena: in case a lower-level phenomenon is the main theme, it can be promoted to the leading position in the compound subject heading. The integration of these principles is believed to produce optimal results in the ordering of knowledge contents.
\end{abstract}

Keywords: Knowledge organization systems. Ontology. Epistemology. Theory of integrative levels. Main theme. Citation order. 


\section{An articulated field}

Knowledge organization (KO) is an interdisciplinary domain with connections to several sciences (philosophy, library and information science, computer science, linguistics, sociology...) (Mcllwaine and Mitchell, 2008). As it includes both theoretical and practical aspects, publications in the field show a wide variety of topics and approaches, from highly abstract ideas to the concrete needs of users in searching and browsing information. Although such variety is indeed a good representation of the different components that are present in our domain, it may appear confusing for those who first approach the field. It is therefore particularly important to provide them with clear descriptions of the scope of $\mathrm{KO}$, of all its components, and of the connections between them.

A tentative model can be provided by a quite simple structure, consisting of four layers each depending on the previous one. The first layer is the most abstract one, including all the theories and approaches to knowledge that draw from such external fields as philosophy of science, hermeneutics, psychology, sociology etc. to either inform the activity of knowledge organizers, or analyze it a posteriori. To this, the layer of knowledge organization systems (KOS) follows; this includes all kinds of schemes like keyword sets, controlled vocabularies, classifications, digital ontologies, etc. While most KOSs are originally conceived for specific local purposes, nowadays they can also be shared at a networked global scale; but this requires a third layer of a technical nature, consisting of such standards and formats as MARC, RDF, SKOS, or OWL, that allow to integrate systems in digital information services and to represent them as exchangeable marked data. This layer seems to have been absent or very limited in KO activity until the end of the $20^{\text {th }}$ century, and is probably the most important novelty in the recent development of KO, as it promises to greatly increase the impact of KOSs on everyday life, by making them interact automatically between each other (mapping) and with information contents. The final layer is that of the application of theories, systems and representation to actual collections of knowledge items, like archives, libraries, exhibitions, and their directories and catalogues, either printed or digital.

Given this multi-layered structure, understanding of the relationships between different layers would especially contribute to the needed consolidation of $\mathrm{KO}$ as a uniform domain. In this paper, I will focus on the first relationship, that between the layer of theories and that of sys- tems. How can KO theories and systems coexist and interact in harmonious and productive ways? How can theory actually affect the development of sound KOSs, rather than remaining confined in a limbo of erudite, self-congratulating speculations?

We will discuss a case of how theories belonging to the ontological and epistemological dimensions of KO can be applied to KOS technical features.

\section{Dimensions in KOSs}

The structure of a KOS is influenced by factors of various nature. These can be ascribed to one or another of the dimensions implicit in $\mathrm{KO}$.

The main acknowledged dimensions in $\mathrm{KO}$ are the ontological one $(\beta)$, dealing with the real phenomena that are studied; the epistemological one $(\mathrm{Y})$, dealing with the perspective (purpose, target, culture, discipline, theory, method, etc.) under which such phenomena are considered and discussed; and the pragmatical ones $(\delta, \varepsilon$, $\zeta)$ dealing with the material aspects of the documents, their collections and their users (Hjørland and Hartel, 2003; Gnoli, 2011).

Knowledge carried by one document usually contains elements of all these dimensions: it deals with some set of phenomena (ontology) under a certain perspective (epistemology) recorded in some document form (bibliography) kept with other documents in a collection (library science, museology etc.) for certain categories of users (sociology).

A KOS, as it is aimed to organize knowledge contained in documents, has to represent these complementary dimensions in some way. Therefore the different dimensions are implicit in any KOS, although its explicit structure may acknowledge only some of them. Traditional systems like bibliographic classifications are often discipline-based, which means that they are primarily structured according to the epistemological dimension: knowledge is first divided according to ways of looking at the world, rather than its object content. That a document is classified under 500 "pure sciences" in the Dewey Decimal Classification (DDC), means that it looks at the world by a certain fundamental perspective, the scientific one, as opposed to alternative perspectives like aesthetic, historical, philosophical, or religious (Mills and Broughton, 1977, Section 5.5; Langridge, 1992). Still, the DDC subdivisions of "pure sciences", like "chemistry", "astronomy" or "zoology", implicitly correspond to classes of phenomena (molecules, stars, animals) considered there in a scientific perspective. 


\section{The ontological approach}

As can be seen, the choice between ontic, epistemic and pragmatic dimensions is one of priority: although they are all present in some way, one of them must be chosen to provide the main structuring principle of a KOS, while the others will be relegated to specifications of it. In some situations, it may be the form of the document that determines the primary subdivisions, like when documents are divided between audiovisual, textual, musical scores etc. for pragmatical reasons. Classifications like DDC and UDC give priority to the epistemic dimension, as they organize disciplines on the basis of human knowledge faculties (the sciences of reason, those of imagination, and those of memory) ultimately derived from the work of Francis Bacon. Other classifications, like Bliss's (BC2) and Colon (CC), though still being disciplinary, order the disciplines by some natural sequence of their objects ("gradation in speciality": philosophy, mathematics, physics, chemistry, biology, etc.), resulting in a more balanced combination of epistemological and ontological factors. This combination can also be found in E. C. Richardson's theory of classification, which advocates listing subjects according to a natural order, that can be approached either ontologically (evolutionary sequence from the simple to the complex) or epistemologically (logical sequence from the complex to the simple) (Dousa, 2010).

In a more substantially ontological approach, the primary subdivisions are given by phenomena themselves: documents dealing with molecules or with animals will be grouped together, irrespective of the epistemic perspective under which these are considered. In this case disciplines, methods, or other perspective facets will be used only as further specifications, as is recommended in the León Manifesto for an interdisciplinary KO (ILC, 2007).

Such an ontological approach may be seen as less advantageous for particular categories of users: an historian would prefer to find all historic books together, rather than scattered under the various phenomena that have been studied by an historical perspective. On the other hand, grouping by phenomena will provide a more complete documentation about each phenomenon, say an indigenous people studied from ecological, demographic, medical, sociological, historical, technological, artistic, or religious perspectives. This will encourage the discovery of new interdisciplinary connections between available knowledge on the same phenomena, which has been described as an added value of classification (Davies, 1989; Szostak, 2008): knowing that an indigenous people has been affected by a certain infectious disease may help to understand taboos in its feeding habits.

The ontological approach (Gnoli, 2009) is a more general and neutral one: it tries to "list the wind where it bloweth", as Jason Farradane put it (Vickery, pers. comm.), that is to list phenomena on the basis of some order identified in the nature of phenomena themselves, rather than in any particular way of looking at them. In this sense it is also naturalistic, as it tries to reproduce a natural "order of things" (Richardson, 1930) rather than to serve any specific purpose. This may the price of allowing less immediate usage for any one specific category of users; but for the same reason its generality will be a better basis on which to found $\mathrm{KO}$ for a wider variety of users and approaches. This was acknowledged by Ernst Mayr (1981), the great theoretical and systematic biologist:

Biological classifications have two major objectives: to serve as a basis of biological generalizations in all sort of comparative studies and to serve as a key to an information storage system. [...] Is the classification that is soundest as a basis of generalizations also most convenient for information retrieval? This, indeed, seems to have been true in most cases I have encountered.

General, ontologically-founded systems also may act as a more neutral reference from which KOSs may be derived for more specific purposes (fitting material constraints of careers, privileging service for some category of users, etc.), by explicitly defining their bias and mapping them to a general system (Wåhlin, 1974), also in view of interoperability needs. Furthermore, as they are more general, such systems may be expected to remain valid for a longer time, apart from the minor changes to stay up-to-date with advances in knowledge that are needed by any system.

\section{One theory for KO: integrative levels}

An important case of an ontological theory that has informed $\mathrm{KO}$ is offered by the theory of integrative levels. This claims that all phenomena of the world belong to one or another in a series of levels, from particles to atoms, molecules, cells, organisms, populations, societies, cultures etc., each developed on the basis of the lower ones, but at the same time showing some emergent property not present in the lower ones (Poli, 2001). The series is often described as one of increasing organization, and roughly also of increasing complexity although simplification may occur locally (e.g. in the evolution of parasites). 
This theory can be found in many philosophical sources, even in the Antiquity, but has become popular in more explicit forms since the $19^{\text {th }}$ century among philosophers of science, including André-Marie Ampère, Auguste Comte, Conwy Lloyd Morgan, George P. Conger, Roy W. Sellars, Theodore Christian Schneirla, James K. Feibleman, Nicolai Hartmann, Bonifatii Mikhailovich Kedrov, and Roberto Poli.

Comte, Ampère and others were acknowledged already by knowledge organizers like Bliss and Bhattacharyya \& Ranganathan (1974) as philosophical sources for their ontologically-oriented "serial" classification systems. It was, however, several members of the Classification Research Group (CRG) who, since the late 1950s, paid special attention to the theory of integrative levels as a major source for building a phenomenon-based KOS (Vickery, 1958; Kyle, 1959; Foskett, 1961; Jolley, 1968; Austin, 1969).

CRG's "general index language" was drafted in its main classes and some examples of subclasses and combinations; however, exhaustion of grants and move of Derek Austin to the British National Bibliography meant that the project was abandoned. The idea has since been resumed by the present author and others, yielding the project of a new system called indeed Integrative Levels Classification (ILC). A first edition of ILC has recently been published on the Web (ILC, 2011) while development and tests continue.

\section{Citation order of levels}

Let us see how the theory of levels applies to the structuring of KOSs in general. First of all, the theory can be applied to the determination of the sequence of main classes in a KOS: classes of phenomena at a lower integrative level will precede those at higher levels in the schedule. This corresponds quite well with the "serial" order in other ontologically-oriented classifications, like BC2, CC, the Broad System of Ordering (BSO), Wåhlin's Universal System, and others. Dahlberg's Information Coding Classification also bases its ten main classes on integrative levels.

Subclasses can also be ordered in a KOS according to their successive appearance in a logical / phylogenetic / historical sequence, as is often done for mathematical entities, organisms, languages, or religions.

Another interesting application of integrative levels comes with the citation order of elements in compound classes. Indeed, many KOSs are synthetic, that is, they allow one to build a verbal heading or a classmark by combining several concepts standing in some relationship between each other. These can be simply juxtaposed, like with the colon symbol in UDC, giving a generic phase relationship such as 5:1 "science (in some relation with) philosophy"; or can be made explicit by role indicators and facets, like in CRG's draft of a "freely faceted" classification or in PRECIS, e.g. "science, discussed in philosophy". So, when these concepts are taken from the schedules and combined freely (that is, with no specification of facet), which order are they to take? Is it science or philosophy that has to be cited first?

Some systems, like DDC, simply prescribe citing the elements in the same order as they appear in the schedules in order to achieve some consistency and predictability of compounds. Other systems, however, try to find a rationale for the order to be adopted. About this, the BSO Manual (Coates et al., 1979) says:

cite first: the notation for the element denoting application area, mission, purpose, end-product or whole system [...];

cite second: the notation for the element denoting aspect, approach, action applied, agent, or part of a stated whole: more generally the subject which 'contributes' an aspect, approach or action.

Use of the above relational formula where the 'aspect contribution' element belongs to the area 210 to 450 [natural and anthropological sciences] will normally produce combination orders which reverse the schedule order, as in the case of internal combinations throughout the schedule. This is because in this area the entities and phenomena studied by a particular science include aspects and properties which essentially belong to other sciences located earlier in the schedule sequence. For instance biological entities may have physical or chemical properties: medical, psychological and social phenomena may have biological aspects. In these cases the roles of 'aspect contributor' and 'recipient' elements cannot be reversed, as long as the 'recipient' element is the primary phenomena [sic] of the subject field concerned.

As BSO schedules follow an ontological sequence close to that of levels, reversing the order of schedules in compounds (in agreement with the inversion principle of facet analysis) also means to cite elements in inverted order of levels. As implicitly acknowledged in the last paragraph, this makes sense as most often the phenomena of lower level, like those studied in chemistry, act as specifications of those of higher level, like those studied in biology.

The opportunity to apply the inversion principle to levels is also acknowledged by Mills (1982, p. 73):

It may be noted that insofar as gradation [in speciality] embodies the principle of levels of 
organization, and insofar as this principle contributes to citation order, the mechanism of inversion also operates at main class level, since the higher level, filing later, is cited first; e.g. Biochemistry is Biology - Chemistry and not viceversa.

Let us assume that the subject of a document be described by a combination of the concepts "genes", "horses" and "breeding". In the light of the theory of integrative levels, the phenomenon at highest level is "breeding", as this is a human activity belonging to technologies, which come after organisms in the list of increasingly organized entities. This means that most documents are expected to deal with genes and horses in the context of breeding, rather than other ways around, and will be best described by the inverted order "breeding: horses: genes".

This also parallels the idea of a logical order of decreasing complexity mirroring the evolutionary order of increasing complexity (see above). One can see decreasing complexity as an epistemological principle, complementary to the ontological one of an evolutionary order (Dousa, pers. comm.): as we humans, in our everyday mesoscopic world, usually deal with relatively complex things at medium-high integrative levels, from plants to artifacts, decomposing them into simpler, microscopic units of lower levels usually is but a further stage in our analysis of things; hence it is discussed, and indexed, only as a specification of more familiar higher-level phenomena. On the other hand, even more complex, macroscopic phenomena such as economic systems or whole cultures are also hard to grasp, and need to be analyzed in literature by deeper discussions.

\section{Citation order of themes}

From what we have said above, a default rule has been inferred: when combining concepts in unspecified relationship, cite first the concepts of higher level, as they usually are the focus of knowledge.

This, however, does not prevent that documents focusing on low levels may exist. Obviously, there are documents dealing only with molecules, or with photons, and these have to be classified under these phenomena. Furthermore, in some documents dealing with both low- and high-level phenomena, a lower-level phenomenon may be the main subject of discussion, while the higher-level ones may be cited only for their relationships with it. Think of a book on the genome of bred horses that deals all the time with the position, replication, and mutation of those genes, mentioning only marginally that they belong to bred horses. In a disciplinary KOS this would be classified as a genetics book, rather than a zoology or an animal science book.

To deal with these cases, a supplementary principle has to be invoked, belonging to the epistemological dimension $\gamma$. In other words, KO should account for the fact that, in that particular treatment, the main theme is genes, while horses and breeding are subsidiary themes that are present only as they are related with the genes under examination (Cheti, 1996).

The notion of theme comes from linguistics, and denotes what is the subject of a sentence or a discourse, as opposed to the rheme, denoting whatever new information is given about the theme. The subject content of our book could be paraphrased as "As for genes of bred horses, they have such and such features". The first half of the paraphrase is the theme, the second is the rheme. Theme usually provides the title of the document as well as its subject content indexed in KOSs (although there may be cases where the rheme is also expressed, like with such journal article titles as "Genes of bred horses are so and so, new research reveals").

Indexing manuals teach how to identify the main theme among the various themes of a document, and to represent them in a KOS. Traditional classifications may do it by phase relationships. Freely faceted systems such as PRECIS and ILC assign the main theme to the leading position, and connect it with the other relevant themes by means of role operators. Therefore, in a freely faceted system, a document will be indexed under the most relevant one among its themes, while the other themes will be expressed in non-leading positions and will also be retrievable by a search. While the documents on "breeding: horses: genes" will be filed together with other documents on breeding, our book on the genetics of bred horses will rather be filed under "genes", having "horses" and "breeding" only as specifications.

This also offers the answer to a criticism moved against phenomenon-based classification, according to which it would be ineffective and even quite absurd to group together documents dealing with horses in genetics, in zoology, in military science, in history of transports or in sculpture, as they will be useful to different scholars. Actually this is more a caricature than a description of what a freely faceted KOS by phenomena really does. Indeed, a citation order based on both integrative levels and main theme will put under "horses" only those documents where horses are the main theme, while the remaining documents will be filed under "genes", 
"weapons", "transports" or "sculpture", and will have "horses" only as a specification.

\section{Conclusions}

We have seen how knowledge organization is made of several layers (theory, systems, representation, application) that should be connected in effective ways. We have analyzed this connection in the case of the application of the theory of integrative levels in systems that adopt it as a structuring principle.

We have also seen how several dimensions concur to form the subject content of documents, and can be represented in subject headings. The most important dimensions are phenomena, perspectives, and carriers. The ontic dimension of phenomena, the epistemic dimension of perspectives, and the bibliographic dimension of carriers interact in the subject of a document. Thus, principles for accurate indexing should come from a wise combination of ontology (e.g. integrative levels), epistemology ("logical order", main theme), and bibliography (medium, format, size etc.). Awareness of the different components will lead to a more effective activity of knowledge organization.

\section{Acknowledgments}

Some ideas for the development of this paper were inspired by a conversation with Tom Dousa. Both Dousa and Keiichi Kawamura suggested useful improvements to a previous version.

\section{Referencias}

Austin, Derek (1969). The theory of integrative levels reconsidered as the basis of a general classification. // Classification and information control / Classification Research Group. London: Library Association. 81-95.

Bhattacharyya, G[anesh]; Ranganathan, S[hiyali] R. (1974). From knowledge classification to library classification. // Wojciechowski, Jerzy A. (ed.). Conceptual basis of the classification of knowledge: proceedings of the Ottawa conference. Pullach bei München: Verlag Dokumentation. 119-143.

Cheti, Alberto (1996). Testo e contesto nell'analisi concettuale dei documenti. // Guerrini, Mauro (ed.). II linguaggio della biblioteca: scritti in onore di Diego Maltese. Milano: Editrice bibliografica. 833-855.

Coates, Eric; Lloyd, Geoffrey; Simandl, Dusan (1979). The BSO Manual: the development, rationale and use of the Broad System of Ordering. FID. Partly republished, University College London, 2002, http://www.ucl.ac.uk/ fatks/bso/manual.htm (2011-08-08).

Davies, Roy (1989). The creation of new knowledge by information retrieval and classification. // Journal of Documentation. 45:4, 273-301.

Dousa, Thomas M. (2010). The simple and the complex in E.C. Richardson's theory of classification: observations on an early $\mathrm{KO}$ model of the relationship between ontology and epistemology. // Gnoli, Claudio; Mazzocchi, Fulvio (eds.). Paradigms and conceptual systems in knowledge organization: proceedings of the Eleventh In- ternational ISKO Conference: Rome, 23-26 February 2010. Würzburg: Ergon. 15-22.

Foskett, D[ouglas] J. (1961). Classification and integrative levels. // Foskett, D.J.; Palmer, B.I. (eds.). The Sayers memorial volume. London: Library Association. 136-150. Republished in Theory of subject analysis: a sourcebook / Chan, Lois M.; Richmond, Phyllis A.; Svenonius, Elaine (eds.). Littleton: Libraries Unlimited, 1985. 210-220.

Gnoli, Claudio (2009). The ontological approach to knowledge organization: invited paper sent for discussion at the 2nd Seminário de Pesquisa em Ontologia no Brasil: Rio de Janeiro, 21-22 September 2009. Instituto militar de engenharia. http://ontobra.comp.ime.eb.br/ ontological.rtf (2011-07-26).

Gnoli, Claudio (2011). Metadata about what?: distinguishing between ontic, epistemic, and documental dimensions in knowledge organization. // Mustafa El Hadi, Widad (ed.). Stabilité et dynamisme dans l'organisation des connaissances: actes du $8 \mathrm{e}$ Colloque International de I'ISKO France: Lille, 27-28 Juin 2011. Hermès Science.

Hjørland, Birger; Hartel, Jenna (2003). Afterword: Ontological, epistemological and sociological dimensions of domains. // Knowledge Organization. 30:3-4. 239-245.

ILC (2007). The León Manifesto. ISKO Italia. http://www.iskoi .org/ilc/leon.php (2011-08-08). Also in: Knowledge Organization. 34:1 (2007) 6-8.

ILC (2011). Integrative Levels Classification. ISKO Italia. Created 2004, updated 2011-07-19. http://www.iskoi.org/ ilc/ (2011-08-08).

Jolley, Leo (1968). Relation codes: an ordering of ideas. // New Scientist. 38:597 (16 May 1968) 338-340.

Kyle, Barbara R.F. (1959). An examination of some of the problems involved in drafting general classifications and some proposals for their solution. // Revue de la Documentation. 26:1, 17-21.

Langridge, Derek (1992). Classification: its kinds, elements, systems, and applications. London: Bowker-Saur.

Mayr, Ernst (1981). Biological classification: toward a synthesis of opposing methodologies. // Science. 214, 510-516.

Mcllwaine, la C.; Mitchell, Joan (eds.) (2008). What is knowledge organization: special issue. // Knowledge Organization. 35:2-3.

Mills, J[ack] (1982). Practice and theory in a general classification: the new Bliss Classification (BC2). // Dahlberg, Ingetraut (ed.). Universal classification: Proceedings of the 4th International Study Conference on Classification Research - 6th Annual Conference of Gesellschaft für Klassifikation e.V.: Augsburg, 28 June-2 July 1982. V. 1. Frankfurt: Indeks. 69-77.

Mills, J[ack]; Broughton, Vanda (1977). Bliss bibliographic classification, Second edition, Introduction and auxiliary schedules. London; Boston: Butterworths.

Poli, Roberto (2001). The basic problem of the theory of levels of reality. // Axiomathes. 12:3-4, 261-283.

Richardson, Ernest Cushing (1930). Classification, theoretical and practical. 3rd ed. New York: Wilson.

Szostak, Rick (2008). Classification, interdisciplinarity, and the study of science. // Journal of Documentation. 64:3, 319-332.

Vickery, B.C. (1958). Classification and indexing in science, Appendix A, Levels of aggregation. London: Butterworths.

Wåhlin, Ejnar (1974). The AR-Complex: adapted systems used in combination with a common reference system. // Wojciechowski, Jerzy A. (ed.). Conceptual basis of the classification of knowledge: proceedings of the Ottawa conference. Pullach bei München: Verlag Dokumentation. 416-449. 